\title{
Análise de Potencial em Tecnologia de Gestão Baseada em Dados de Mídias Sociais e Tendências - TRENDS
}

\author{
Analysis of Potential on Management Technology Based on Social \\ Media Data and Trends
}

\author{
Fabrício de Andrade Raymundo ${ }^{1}$ \\ Eduardo Antonio Ferreira ${ }^{1}$ \\ Sônia Marise Salles Carvalho ${ }^{1}$ \\ Tânia Cristina Cruz ${ }^{1}$ \\ Leila Fernandes dos Santos ${ }^{1}$ \\ Marcio Lima da Silva ${ }^{1}$ \\ ${ }^{1}$ Universidade de Brasília, Brasilia, DF, Brasil
}

\begin{abstract}
Resumo
O presente artigo trata-se de análise acerca de tecnologias de gestão baseada em dados de mídias sociais e tendências trends. O meio empresarial vem utilizando tecnologias de análises de dados oriundos das plataformas de mídias sociais a fim de aprimorar sua produção e melhorar a relação com os usuários (clientes). Utilizou-se como metodologia a tendência de pesquisa, medida pela produção de artigos científicos, em conjunto com a análise de registro de patentes. A busca principal apresenta detalhes coletados junto às bases Web of Science (artigos) e Espacenet (patentes) e em um complemento de pesquisa com encaminhamento de sugestão para trabalhos semelhantes futuros pesquisou-se nas bases: Espacenet e Patentscope, Web of Science e Google Acadêmico. Os resultados revelaram que a tecnologia em questão se encontra em nível avançado de desenvolvimento, consolidada, mas em constante atualização, em virtude dos dados e de os atores identificados relacionados à tecnologia estarem em constante modificação.
\end{abstract}

Palavras-chave: Mídias Sociais. Prospecção Tecnológica. Trends.

\begin{abstract}
This paper is an analysis of management technology based on social media data and trends. Companies has been using data analytics technologies from social media platforms to enhance their production and improve relationships with users (customers). The research methodology used was a research trend, measured by production of scientific articles, linked with the patent registration analysis. Main research presents details collected on Web of Science (articles) and Espacenet (patents) databases, in complement this research presents suggestion forwarding for similar future papers, following databases: Espacenet, Patentscope, Web of Science and Google Scholar were used. Results revealed that the technology in question is in advanced level of development, consolidated, but constantly updated because data and technology-related actors are constantly changing.
\end{abstract}

Keywords: Social media. Technological Foresight. Trends.

Área Tecnológica: Processos da Comunicação. Modelos Analíticos e de Simulação. Processos de Disseminação da Informação. 


\section{Introdução}

A possibilidade das companhias em ajustar suas entregas, baseadas em pesquisas de opinião junto aos usuários, já é uma realidade; no entanto, em um cenário dinâmico e global, em que estão cada vez mais efêmeras as mudanças, focar nas tendências encontradas no terreno virtual (rede web) e integrá-las ao processo de tomada de decisão das empresas têm se tornado bastante relevante.

A utilização de ferramentas de prospecção de tendências, aplicadas à gestão das organizações, é possível e primordial no contexto da tomada de decisões. A percepção de que o mundo empresarial necessita a todo instante aprimorar-se, inovar-se, relacionar-se com o mercado e, especialmente, prospectar tendências, a fim de se ajustar ao seu público (usuário final), é importante para as organizações (OLIVEIRA; CARVALHO, 2013).

Maslow (1943) defende que as necessidades humanas estariam dispostas em níveis e hierarquicamente organizadas com escala de valor, e o ser humano, por sua vez, em constante busca por satisfazê-las. Nos tempos atuais, a realidade apresentada pelo autor é cada vez mais evidente.

Segundo Zackiewicz (2015), há a necessidade de medir a digitalização da sociedade e as atividades econômicas, determinar a taxa de avanço da parcela imaterial na geração de valor e monitorar a propensão e a velocidade da concentração e da inovação.

Segundo o ponto de vista de Simmons (2008), a internet seria o meio ideal para isso, e ela vem ganhando relevância na qualidade de ferramenta de marketing pelo fato de estar se revelando como a forma mais adequada para dar resposta às complexidades inerentes ao consumidor pós-moderno, que procura experiências de consumo com produtos tanto em grupo quanto individualmente.

Heiko et al. (2011) entendem que a internet precisa evoluir para a criação da "era da colaboração". Para este propósito, o design de sistemas de apoio prospectivo passou a ser visto como crucial, pois considera os aspectos de comunicação e análise estatística e qualitativa dos dados, incluindo avaliações de especialistas, modelagem de decisão e regras de ordem.

Com o escopo de assessoramento na gestão de empresas por meio de identificação-contextualização-avaliação-aplicação do produto final focado na opinião do cliente, é trazido à luz o interesse do uso de ferramentas de simples utilização, adaptadas ao comércio, às indústrias etc., capazes de aferir, junto ao público geral, as demandas atuais e de facilitar a tomada de decisão no meio empresarial, melhorando estratégias de Pesquisa e Desenvolvimento (P\&D), reduzindo a possibilidade de insucesso e melhorando o relacionamento entre empresas e clientes. "Atualmente, existem diversas plataformas de mídia social que variam em funcionalidades, grupos de usuários e escopo, mas são fontes importantes de acesso em tempo real à opinião pública" (KIETZMANN et al., 2011, p. 242).

Por meio de ferramentas gratuitas disponíveis em "fonte aberta" na rede web mundial, é possível integrar e avaliar, em determinados períodos, os compartilhamentos das pessoas conectadas às mídias sociais (DE MORAES; SANTOS, 2013).

Em seu estudo, Kayser (2016) examina fontes da internet e mídias sociais para usá-las em previsões (predictions). O trabalho da autora concentrou-se na plataforma Twitter devido à 
diversidade de atores contribuintes, como, por exemplo, indivíduos, associações e empresas, elaborando possíveis aplicações no contexto da previsão.

Não há uma forma comum que tenha prevalecido ao realizar a análise de dados do Twitter, enquanto se tem disponíveis esforços qualitativos e quantitativos (KAYSER apud BRUNS; BURGESS, 2012). No decorrer do seu artigo, a autora apresenta duas estratégias para obter dados, que são diferenciadas e apresentadas na Figura 1.

- Busca de dados (1); ou

- Engajamento ativo (2).

O primeiro depende de uma estratégia de pesquisa (Figura 1), enquanto o segundo depende do lançamento de uma discussão. Isto é seguido pela coleta de dados e análise, enquanto uma interpretação dos resultados é geralmente o último passo.

Para compreender a pesquisa deste trabalho, é fundamental perceber a conexão estabelecida entre os perfis das empresas e os prestadores gratuitos de mídias sociais, a exemplo do Twitter. Essa conexão ocorre via Application Programming Interface (API) - traduzido para o português, chama-se Interface de Programação de Aplicativos.

Uma API é criada quando uma empresa de software tem a intenção de que outros criadores de software (empresas do mercado, por exemplo) desenvolvam produtos associados ao seu serviço. Existem vários deles que disponibilizam seus códigos e instruções para serem usados em outros sites da maneira mais conveniente para seus usuários (TECH, 2019).

Considerando-se o modelo apresentado por Kayser (2016) e o fato de que as conexões entre mídias sociais e os respectivos perfis públicos das empresas com os usuários (clientes) são disponibilizadas por meio de APIs, as terminologias Analysis e API passam a ser sugeridas a integrarem-se ao desenvolvimento de estudos e às proposições de novas pesquisas futuras.

Figura 1 - Estratégia para obtenção de dados na mídia social Twitter

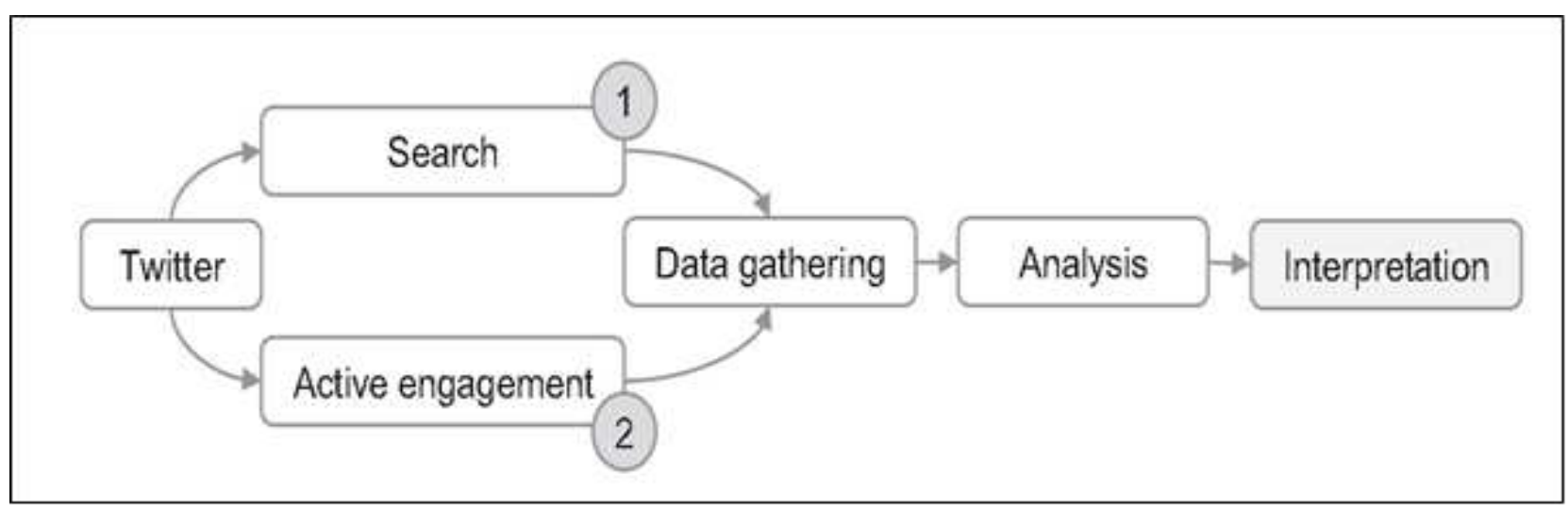

Fonte: Kayser (2016, p. 52)

Em síntese, a presente pesquisa busca analisar esse tipo de tecnologia quanto à sua inovação e a viabilidade de se incrementar tecnologias porventura existentes utilizadas no contexto do assessoramento - para gestão de empresas - baseadas em mídias sociais (opinião do cliente) e tendências. 
Identificaram-se patentes e documentos relacionados às tecnologias de mídias sociais e tendências encontrados em bases de pesquisas acadêmicas e de patentes (Google Acadêmico, Web of Science, Patentscope e Espacenet), verificou-se a existência e, ainda, a que área do conhecimento estas tecnologias estão relacionadas (com foco em áreas de gestão, tomada de decisões, mercado, negócios dentre as principais) com o objetivo de se chegar aos dados analisados e discutidos neste trabalho de prospecção.

\section{Metodologia}

Este trabalho foi realizado por meio de pesquisa qualitativa descritiva, em bases de dados bibliográficos, com o objetivo de apresentar um mapeamento sobre ferramentas de análise de dados compartilhados em mídias sociais e a interpretação deles - as trends ou tendências - para o uso na aproximação entre o cliente (usuário) e o tomador de decisões das corporações.

Por meio do método quantitativo, foi possível organizar e analisar as informações coletadas de trabalhos sobre as temáticas das mídias sociais, da interpretação dos dados e dos produtos disponíveis no mercado, neste modelo de consolidação de tendências, discutidas em fontes abertas pessoais (mídias sociais), com o intuito de entender se é possível, por meio dessas tecnologias existentes, melhorar o estágio atual de aproximação da produção industrial e seus gestores à opinião dos clientes e usuários.

O método qualitativo complementa a pesquisa, tendo em vista a interpretação dos achados pelos autores (estudante e professores do Programa de Pós-Graduação em Propriedade Intelectual e Transferência de Tecnologia para a Inovação - PROFNIT), e apresenta a visão interpretada baseada nesses achados. Essa visão complementa esta pesquisa.

Os itens abaixo pormenorizam a parte procedimental deste trabalho.

1) Mapeamento por meio de revisão técnica da literatura sobre a temática da prospecção de tecnologias para a gestão focada no relacionamento com os consumidores. Pretende-se mapear a tecnologia utilizando-se bases de dados disponíveis na internet (Google Acadêmico, Web of Science, Patentscope e Espacenet).

2) Definição do refinamento para delimitação do caminho da pesquisa por meio dos argumentos de busca trend* and social medi*.

3) A fim de se obter um melhor filtro em relação às efetivas características e aplicabilidades para verificação de pertinência da rota estudada, delimitou-se a pesquisa de tecnologia baseada em mídias sociais e tendências. Por meio de filtros, focou-se em áreas como gestão, computação, mercado, negócios dentre as principais com o objetivo de chegar aos dados a serem analisados e apresentados por meio do Gráfico 1.

4) Interpretação dos achados, objetivando entender a possibilidade de integração das tecnologias mapeadas (inovação incremental).

5) Sugestão de palavras-chave para novos mapeamentos de tecnologias semelhantes voltadas para o assessoramento baseado em mídias sociais e tendências, objetivando reproduzir pesquisas com outros truncamentos e recuperando outros documentos com conteúdos semelhantes a esta pesquisa. 
Este trabalho, por meio da metodologia apresentada, se deu entre março e julho de 2019, por meio de coleta em base de periódicos e patentes, prioritariamente, e identificou a relevância do tema para o contexto da propriedade intelectual e da inovação.

\section{Resultados e Discussão}

Alinhado aos parâmetros apresentados na metodologia, fazendo-se uso do truncamento principal desta pesquisa, o qual apresenta os seguintes argumentos: trend* and social medi*, apresentamos a discussão dos resultados.

O primeiro resultado, após a aplicação dos filtros apontou o número de 1.132 (mil cento e trinta e dois) registros na base Web of Science com estatísticas mais significativas a partir do ano 2013. Por meio desses filtros, chegamos aos resultados, constantes nos Gráficos 1 e 2 e na Tabela 1.

Os achados no Gráfico 1 apontam para trabalhos, em sua maioria, das áreas de Comunicação e, em segundo lugar, da área de Ciência da Computação e Sistemas de Informação. Em terceiro lugar, aparecem trabalhos relacionados à Teoria e Métodos da Ciência da Computação, e, em quarto lugar, temos a temática Negócios, também com grande relevância para a área da propriedade intelectual. Ciências da computação-inteligência artificial e gestão aparecem na sequência; estas também áreas-objeto da gestão estratégica do mercado. Economia, negócios financeiros, ciências da computação e aplicações interdisciplinares, ciências da computação e engenharia de software, administração pública, desenvolvimento de planejamento estatístico e probabilidade e demografia fecham a lista dos resultados.

Infere-se, a partir dos resultados obtidos, que a tecnologia buscada é coerente e compatível com a temática pesquisada, considerando-se as áreas de comunicação, gestão, negócios e as decorrentes da informática e do desenvolvimento de programas. Compreende-se, portanto, que estas áreas representam o núcleo core que sustenta, independentemente da empresa, o estabelecimento da relação empresa e cliente por meio da gestão da opinião do usuário.

Gráfico 1 - Pesquisa na base Web of Science, trend* and social medi* e resultados por área do conhecimento após a aplicação dos filtros

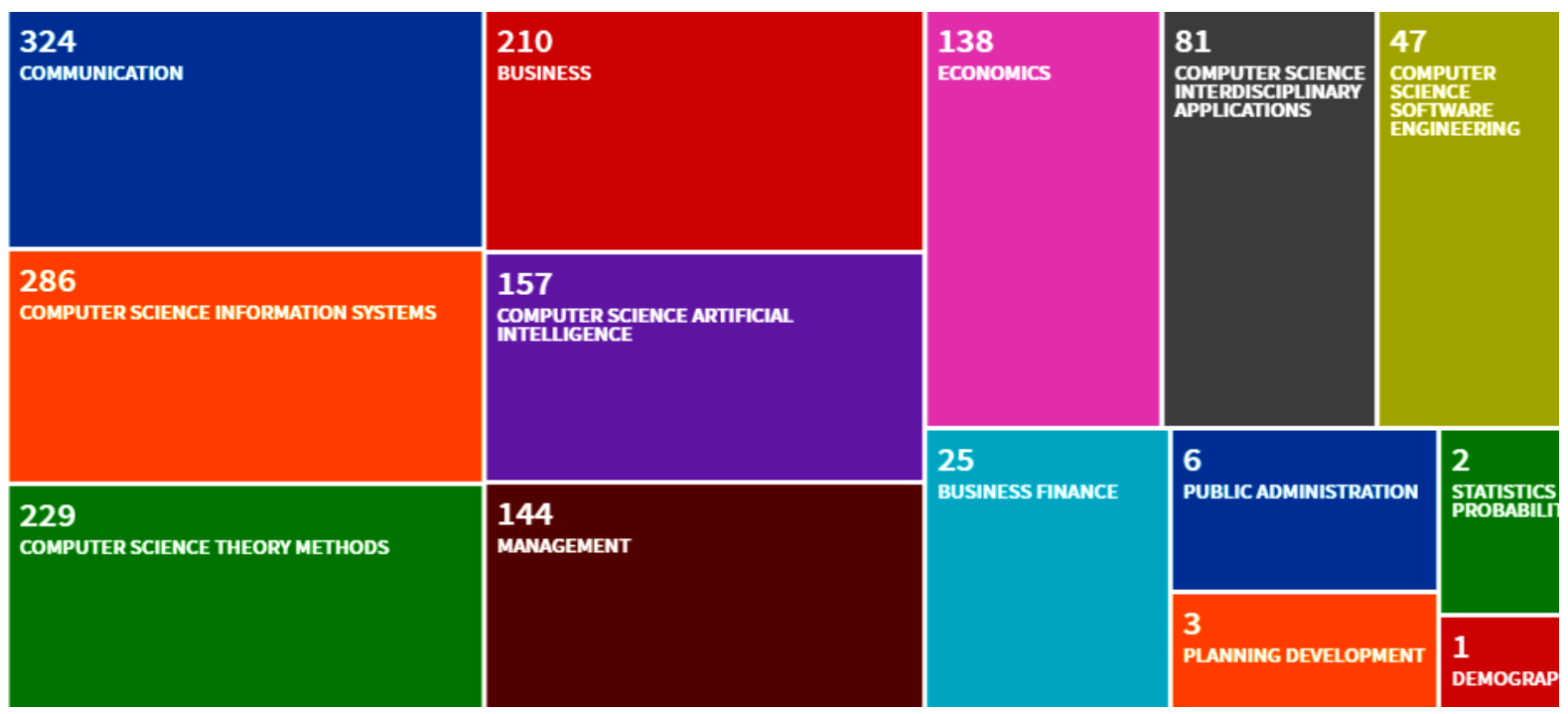

Fonte: Elaborado pelos autores deste artigo (2019) 
Por meio do Gráfico 2 e da Tabela 1, verifica-se a citação de trabalhos, em sua maioria ocorridos no ano de 2018 (197 citações). Em ordem decrescente temos 2016 (192 citações), 2017 (187 citações), 2015 (146 citações) e 2014 (91 citações). Esses representam 71,80\% do total de registros na base Web of Science. Cabe ainda ressaltar que o ano de 2019 já apresenta, em seus primeiros seis meses, uma boa representatividade, com 71 registros e $6,30 \%$ do total de publicações.

Gráfico 2 - Pesquisa na base Web of Science, trend* and social medi*e resultados do número de trabalhos entre os anos de 1994 e 2019, após a aplicação dos filtros

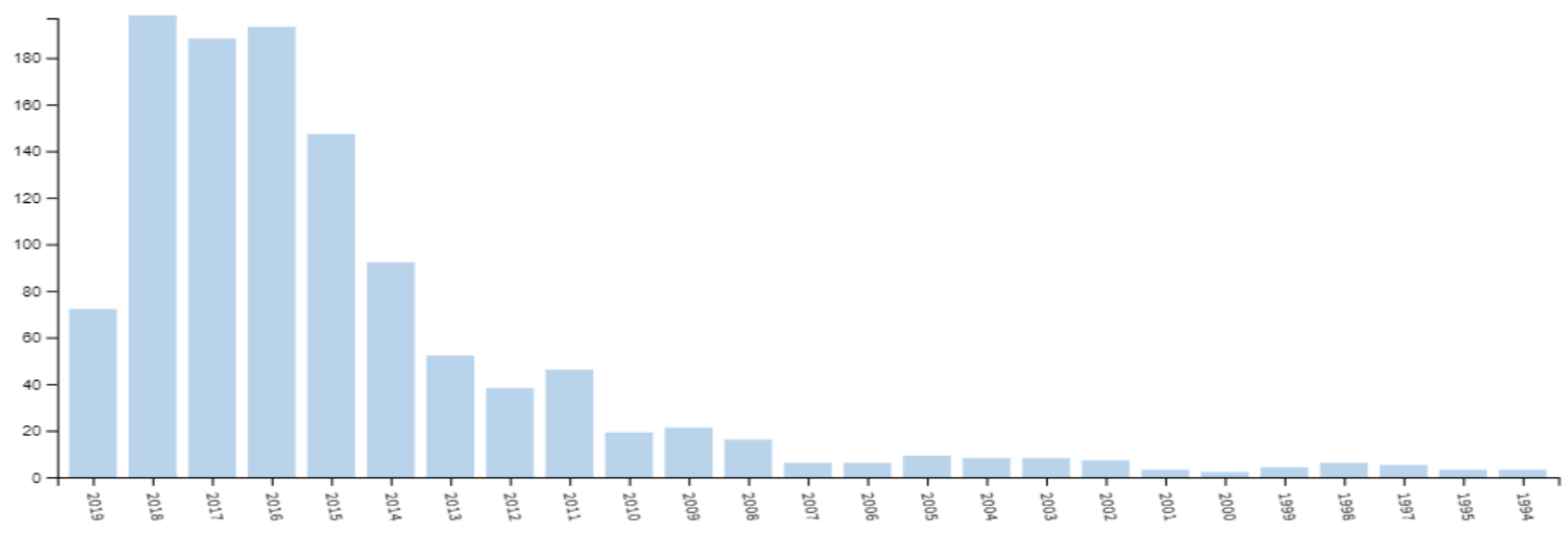

Fonte: Elaborado pelos autores deste artigo (2019)

Tabela1 - Pesquisa na base Web of Science, trend* and social medi* e resultados do número de citações entre os anos de 1994 e 2019 e percentual no número de registros encontrados, após a aplicação dos filtros

ANOS DE PUBLICAÇÃO

2019

2018

2017

2016

2015

2014

2013

2012

2011

2010

2009

2008

2007

2006

2005
REGISTROS (1132)

71

197

187

192

146

91

51

37

45

18

20

15

5

5

8
\% DE REGISTROS

6.30

17.40

16.50

16.96

12.90

8.03

4.50

3.30

3.95

1.60

1.80

1.30

0.40

0.40

0.70 


$\begin{array}{lll}2004 & 7 & 0.60 \\ \mathbf{2 0 0 3} & 7 & 0.60 \\ \mathbf{2 0 0 2} & 6 & 0.50 \\ \mathbf{2 0 0 1} & 6 & 0.20 \\ \mathbf{2 0 0 0} & 2 & 0.10 \\ \mathbf{1 9 9 9} & 1 & 0.30 \\ \mathbf{1 9 9 8} & 3 & 0.40 \\ \mathbf{1 9 9 7} & 5 & 0.35 \\ \mathbf{1 9 9 5} & 5 & 0.20 \\ \mathbf{1 9 9 4} & 4 & 0.20\end{array}$

Fonte: Elaborada pelos autores deste artigo (2019)

Como se observa no Gráfico 2 e na Tabela 1, na década de 1990 e até em meados dos anos 2000, as pesquisas eram pouco representativas em termos estatísticos (ano de 1994 a 2007). Outra constatação a ser reportada é a ascensão ininterrupta do número de trabalhos a partir do ano de 2013 até o ano de 2017.

A leitura que se pode fazer dos dados expressos é a de que há um crescente interesse na temática pesquisada. Trabalhos acadêmicos relacionados às mídias sociais e a tendências apresentam relevância expressa pelos números analisados sobre o mundo acadêmico.

$\mathrm{Na}$ distribuição entre os países, demonstrada no Gráfico 3, verifica-se que o país com maior número de registros é o Estados Unidos da América (EUA), com 274 registros, o que corresponde a 24,21\% do total de trabalhos analisados. Em segundo lugar, com 95 trabalhos (8,40\%), encontra-se a China, seguida da Espanha (64 trabalhos - 5,66\%) e da Austrália (60 trabalhos $-5,30 \%$ ).

Os resultados apresentam-se semelhantes aos achados de De Abreu Pereira Pinto et al. (2016, p. 33), pois, "além dos Estados Unidos, China, Alemanha, Nova Zelândia e Inglaterra foram os países com maior número de publicações na área".

A Inglaterra possui 58 trabalhos (5,12\%), a Índia possui 48 trabalhos e a Itália possui 47, perfazendo, respectivamente, 4,24\% e 4,15\% dos trabalhos. A lista termina com 12 trabalhos de Singapura (1,0\% da pesquisa). Em relação ao último colocado, o Brasil se situa um pouco mais acima no ranking, com apenas 15 trabalhos de pesquisa (1,33\%).

O Brasil é um país no qual o uso de mídias sociais através de smartphones vem se desenvolvendo; porém, em relação a traduzir essa realidade do uso em produções científicas, vemos a pequena representatividade de documentos intelectuais atinentes à área. As duas maiores economias do mundo (China e EUA) apresentam índices compatíveis com a importância dos mercados que representam. 
Gráfico 3 - Pesquisa na base Web of Science, trend* and social medi* e quantidade de trabalhos por países, após a aplicação dos filtros
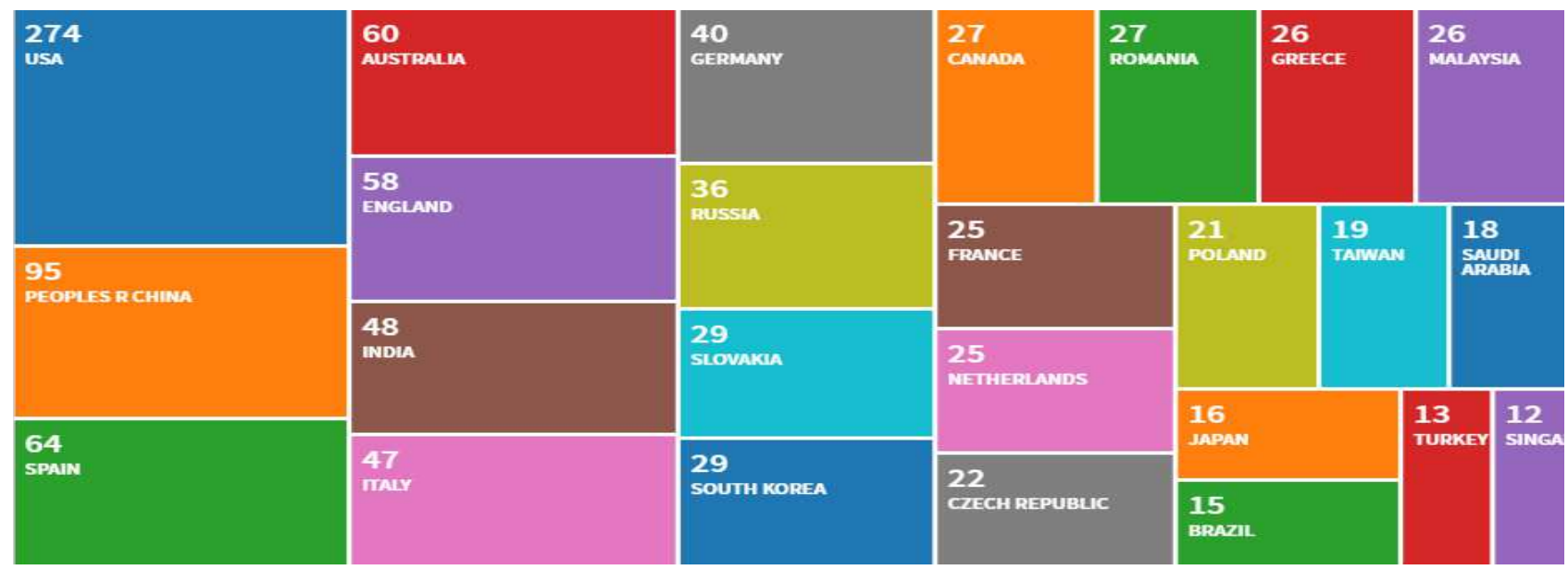

Fonte: Elaborado pelos autores deste artigo (2019)

Os documentos encontrados no Web of Science - coleção principal e avaliados neste trabalho de análise estão divididos conforme se pode observar no Gráfico 4. Trata-se de artigos (627 trabalhos, sendo 55,39\% do total), papéis de procedimento ( 457 trabalhos, sendo 40,37\% dos resultados), revisões (38, sendo $3,36 \%$ do total), material de editorial ( 13 , sendo $1,15 \%$ do total) e cartas (10 e 0,88\% do achado). Aparecem ainda 3 edições de livros (0,27\% dos trabalhos), 1 artigo de acesso antecipado e 1 nota, ambos perfazendo 0,09\% dos trabalhos encontrados, cada.

A predominância de artigos que representam mais da metade do total de documentos reflete a característica dinâmica da evolução e do interesse na temática pesquisada.

Gráfico 4 - Pesquisa na base Web of Science, dividida por tipo de trabalho

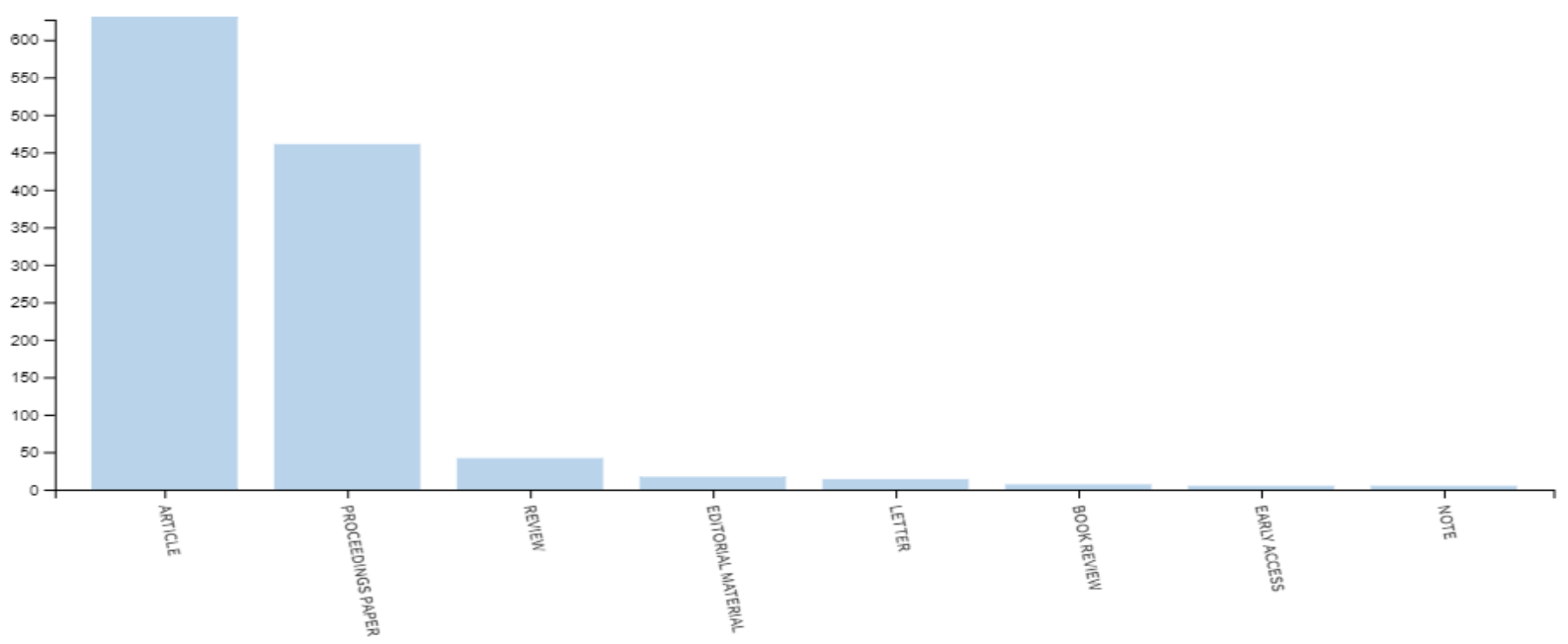

Fonte: Elaborado pelos autores deste artigo (2019)

A busca na base de patentes Espacenet está apresentada por meio dos Gráficos 5, 6 e 7 . Utilizaram-se as mesmas palavras-chave: trend* and social medi*. 
O Gráfico 5 aponta um total de 182 registros, dos quais temos 111 resultados de patentes nos Estados Unidos da América, 41 patentes na China, 9 resultados no World Intellectual Property Organization (WIPO), 8 na República da Coréia e 3 resultados no Japão. Taiwan, Canadá e Reino Unido apresentam 2 resultados cada. Por fim, a Organização Europeia de Patentes (OPE), as Filipinas, a Austrália e a Rússia finalizam a lista com 1 registro cada.

Os resultados apresentados são os achados da pesquisa realizada com base nas mesmas palavras-chave, consultadas na base Espacenet trend* and social medi* delimitadas inicialmente para o objeto da pesquisa. Por meio dessa estatística, podemos visualizar, assim como no banco de trabalhos científicos, que os dois atores, EUA e China, coincidem na liderança de registros no banco Espacenet.

Não foram encontrados registros com sede no Brasil. Por meio desse dado, podemos entender que os achados de patentes e acervos acadêmicos são bastante semelhantes; isso significa dizer que são pouco ou nada representativos.

Gráfico 5 - Pesquisa na base Espacenet, trend* and social medi* e resultados do número de patentes por países e respectiva quantidade

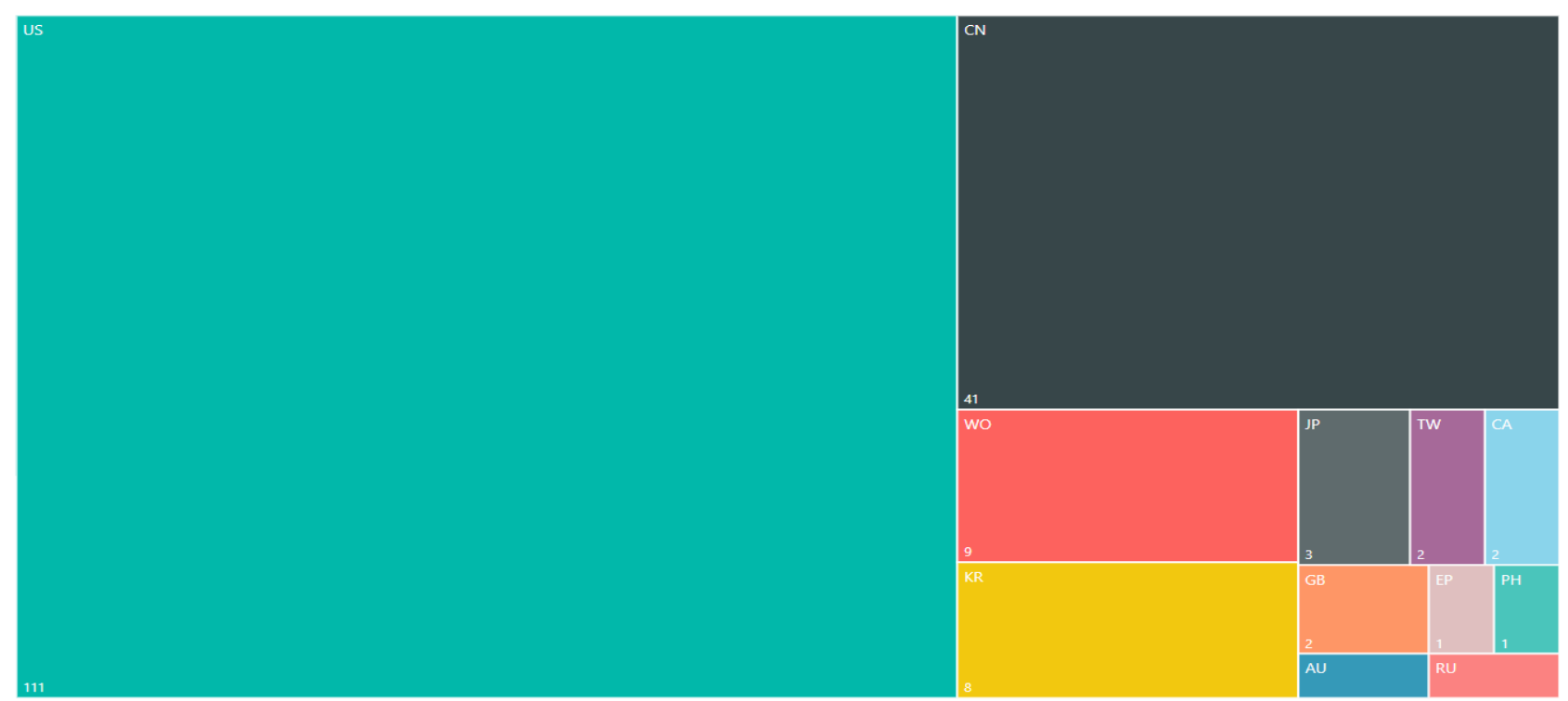

Fonte: Elaborado pelos autores deste artigo (2019)

Por meio do Gráfico 6, é possível também perceber um aumento das patentes, pós-advento de lançamento da mídia social Twitter e de popularização desta categoria de programas criadores de redes sociais virtuais, especialmente na última década. Percebe-se um aumento das patentes a partir do ano de 2012 até o ano de 2015, ano do ápice. O ano de 2019, ainda na metade, a exemplo da pesquisa no banco de trabalhos acadêmicos, também é promissor e já está numericamente empatado com o total de patentes do ano de 2018.

Ao se verificarem as nacionalidades segmentadas por ano de concessão, temos novamente o destaque para os EUA, no Gráfico 6, representado pela cor amarela. 
Gráfico 6 - Pesquisa na base Espacenet, trend* and social medi* e resultados do número de trabalhos separados por ano - entre 1994 e 2019 e respectivos países

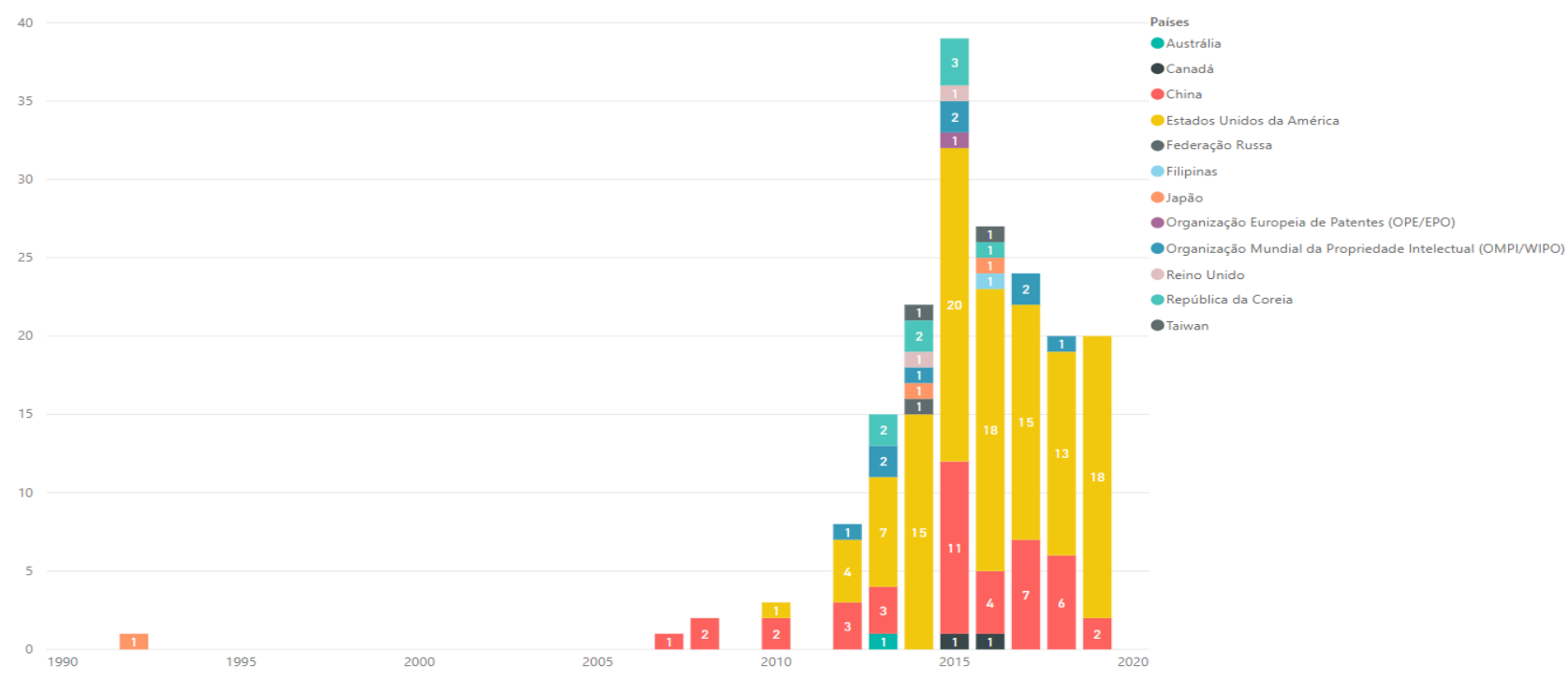

Fonte: Elaborado pelos autores deste artigo (2019)

O Gráfico 7 revela os maiores detentores das tecnologias encontradas na pesquisa junto à base de dados de patentes Espacenet. Os resultados corroboram para a realidade da busca, propósito da pesquisa - tecnologias para verificação de tendências em mídias sociais. O fato que chama atenção ao analisar os dados encontrados é que empresas relacionadas a desenvolvimento de tecnologia e uma grande empresa do varejo dos Estados Unidos encontram-se no topo do ranqueamento (IBM e Walmart). Em seguida, encontramos a Microsoft Inc, Rovi Guides Inc, Adobe Systems Inc e Avaya Inc na sequência de patentes encontradas, todas estas oriundas dos EUA. Ainda na lista observa-se, em $9^{\circ}$ lugar, a empresa que possui o maior número de usuários conectados, formando a maior rede social do planeta, o Facebook.

Estes achados, trazidos para a realidade brasileira, são coerentes às análises de Serra et al. (2013, p. 244-245): "estima-se que praticamente todas as grandes empresas presentes no Brasil irão aderir às mídias sociais até 2015, sendo seguidas por mais da metade das empresas de médio porte". 
Gráfico 7 - Pesquisa na base Espacenet, trend* and social medi* e resultados de patentes separados por detentor - entre 1994 e 2019

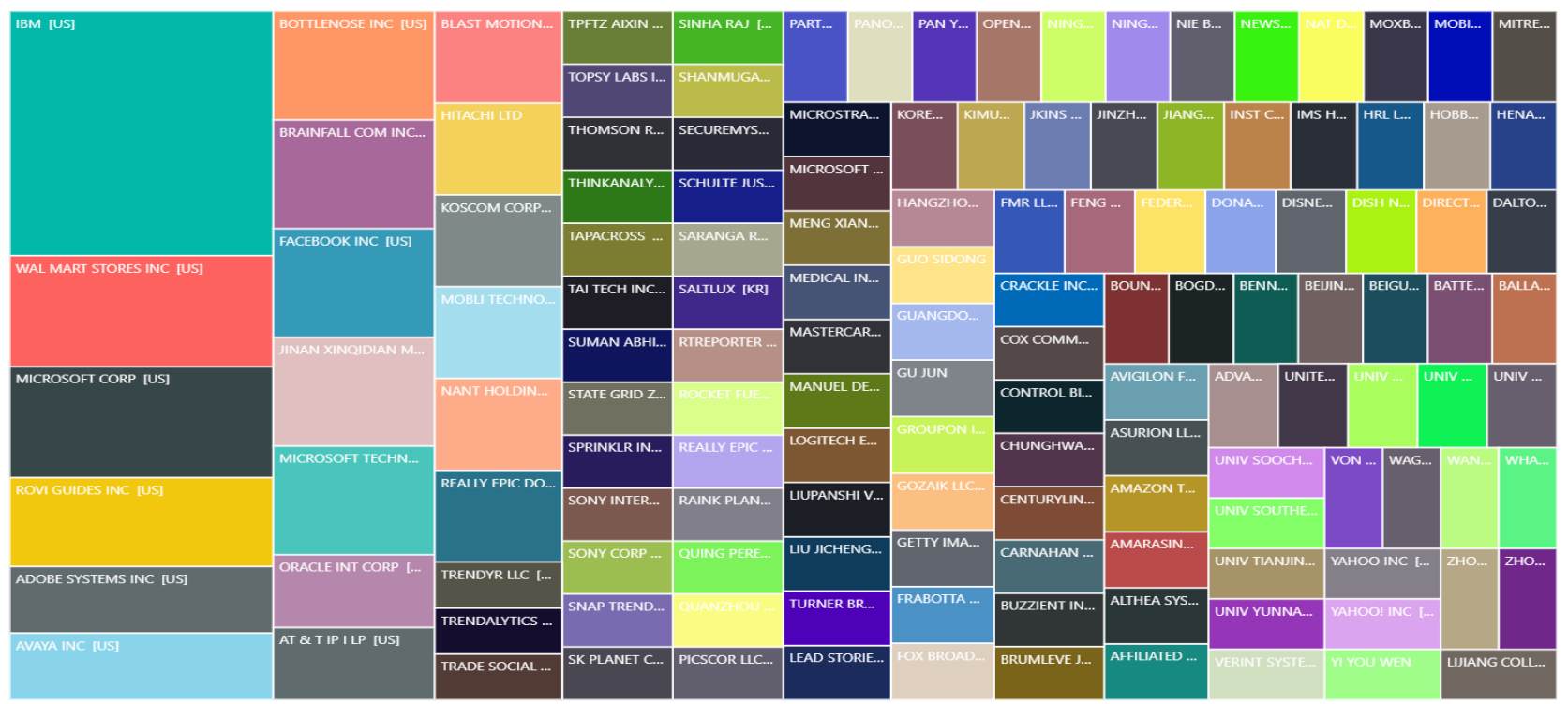

Fonte: Elaborado pelos autores deste artigo (2019)

A partir dos resultados obtidos com o refinamento trend* and social medi*, comprovada a pertinência dessa pesquisa voltada para a verificação de potencial de incremento de tecnologias de avaliação de tendências em mídias sociais para assessoramento, passou-se a relacionar junto aos resultados o potencial de outros refinamentos que poderiam estar relacionados a esta temática e que sejam, a título de sugestão, objeto de outras pesquisas de prospecção futuras.

As constatações reveladas, tanto nos resultados das buscas em bancos de patentes quanto nos bancos acadêmicos e aqui processadas, especialmente no que tange às datas de aumento do número de trabalhos, são coerentes com o trabalho de Simmons (2008), que apresentou, como um dos raciocínios do seu artigo Marketing to postmodern consumers: introducing the internet chameleon, o seguinte:

O surgimento de sites de redes sociais e conteúdo gerado pelo usuário em inglês - user-generated content (USG) - forçou comerciantes para despertar para as oportunidades que estão sendo criadas para suas marcas no mundo pós-moderno. Essas redes virtuais podem ser organizadas em torno de vários nichos de interesse ou conteúdo e estão se tornando muito parte de conversas diárias em sociedade pós-moderna. (SIMMONS, 2008, p. 305)

Esse trabalho foi publicado em 2008, há pouco mais de uma década - ano em que as mídias sociais ainda não tinham a importância e a sedimentação como têm nos tempos atuais. No entanto, o olhar para a influência e a participação das tecnologias relacionadas às mídias sociais já era entendido como uma oportunidade. Os demais achados deste trabalho apontam, além de oportunidade, para o uso de ferramentas web que se relacionam ao usuário e hoje fazem parte da realidade de empresas, independentemente do ramo a que se dedicam.

O incremento na produção de artigos, a partir do ano de 2008, e nos depósitos de patentes, a partir de 2012, apresentado nesta pesquisa, revelou que o interesse nas pesquisas e nas produções relacionadas à tecnologia é progressivo e com tendência à manutenção desse status. 
Observou-se, diante dos achados, que o mundo empresarial e acadêmico apresenta atores bem posicionados que atuam ou são clientes das tecnologias que envolvem a gestão dessas companhias e a percepção dos usuários, independentemente do setor em que estas atuam fato que, por meio dos gráficos anteriores, restou constatado.

\subsection{Análise SWOT}

A partir do levantamento de dados, foi possível elaborar uma matriz de indicadores organizada em quatro setores: Forças, Fraquezas, Oportunidades e Ameaças, atinentes a este mapeamento, conforme apresenta a tabela 2. Por meio da análise SWOT, demonstra-se, de forma lógica, que a tecnologia pesquisada apresenta um bom equilíbrio (com leve vantagem para as Forças), se for tomada como referência a relação Forças x Fraquezas.

Da mesma forma, a relação Oportunidades x Ameaças apresenta-se equilibrada, ainda que também em vantagem, se for levado em conta que o quesito Ameaças considera variáveis que são vitais para a sobrevivência da interface do fornecedor dos dados, ou seja, que dificilmente seriam negadas aos atores envolvidos no desenvolvimento da tecnologia.

Tabela 2 - Matriz SWOT para tecnologia de assessoramento baseada em mídias sociais e tendências trends

Tecnologia aplicável a diversas áreas do conhecimento;

FORÇAS

(strenghts)

FRAQUEZAS

(weaknesses)

OPORTUNIDADES

(opportunities)
AMEAÇAS

(threats)

\section{Comunicação do mercado com uma boa amostra dos usuários (clientes); Tecnologia aberta a incrementos (melhoramentos) de acordo com o modelo de negócio.}

Dependência da tecnologia das mídias sociais;

Dependência do engajamento ativo cliente, ou da promoção do debate para obtenção do dado.

Quanto mais usuários de mídias sociais vinculado ao produto, mais dados para o assessoramento da gestão; Possibilidades de múltiplas aplicações: P\&D (pesquisa de mercado), aumento e permanência de produção, comunicação, marketing, dentre outros.

Tecnologia consolidada, mas em constantes atualizações; Depende de liberação de dados de outra companhia (detentora da mídia social).

Fonte: Elaborada pelos autores deste artigo (2019)

\subsection{Sugestões para Pesquisas Futuras}

Após serem verificadas evidências de possibilidade de incremento e melhoramento da tecnologia analisada, esta parte do trabalho de mapeamento, que antecede as considerações finais, focou em abrir o campo pesquisado para que outros trabalhos individualizados sobre essa temática sejam desenvolvidos em detalhes nestes outros refinamentos, devido à vasta produção encontrada.

Conforme demonstraram Quintella et al. (2011), "[...] tecnologias afins também são buscadas e podem ser incorporadas à tecnologia que está sendo mapeada, formando parcerias com alto potencial de sucesso, podendo aumentar seu impacto sinérgico". 
Para tanto, levando-se em conta o produto tecnológico mapeado, as Tabelas 3, 4 e 5 apresentam os dados com os resultados de sugestões de buscas com refinamentos que guardam relação à busca inicial e às alterações com seis sugestões afins, que são: trend* and social medi*; trends and social media; trending and social network; social media and analysis; API (social medi* and API); ou social medi* and analysis. Essas são as que mais se aproximam aos achados, bem como o enfoque deste trabalho.

Por meio das Tabelas 3, 4 e 5, foi feita uma avaliação geral com as palavras-chave que estariam relacionadas ao objeto de pesquisa. As tabelas estão categorizadas individualmente, de acordo com o banco de dados pesquisado.

A Tabela 3 apresenta o resultado geral da pesquisa de patentes na base de dados mundial do Espacenet.

Tabela 3 - Resultado geral da pesquisa de patentes na base de dados do Espacenet - worldwide database.

\begin{tabular}{cc} 
Palavras-chave & EsPaCenET \\
Trend* and social medi* & 182 \\
Trends and social media & 79 \\
Trending and social network & 46 \\
Social media and analysis & 643 \\
API & Acima de 10.000 \\
Social medi* and analysis & 870 \\
\hline
\end{tabular}

Fonte: Elaborada pelos autores deste artigo (2019)

A Tabela 4 apresenta o resultado geral da pesquisa de patentes na coleção principal da base Web of Science (segunda coluna) e banco de dados de patentes e citações do Google Acadêmico (terceira coluna). Na quarta coluna, a tabela expressa o total de registros encontrados de acordo com a palavra-chave utilizada.

Tabela 4 - Números de publicações em diferentes bases de dados e resultado

\begin{tabular}{cccc} 
Palavras-chave & $\begin{array}{c}\text { Web of SCIENCE } \\
\text { (COLEÇÃo PRINCIPAL) }\end{array}$ & $\begin{array}{c}\text { Google AcadÊMICo } \\
\text { (PATENTES E CITAÇõEs) }\end{array}$ & TOTAL \\
Trend* and social medi* & 8813 & 645.000 & 653.813 \\
Trends and social media & 4271 & 3.920 .000 & 3.924 .271 \\
Trending and social network & 5173 & 107.000 & 112.173 \\
Social media and analysis & 28010 & 4.280 .000 & 4.308 .010 \\
Social medi* and API & 422 & 29.300 & 29.722 \\
Social medi* and analysis & 68309 & 1.610 .000 & 1.678 .309 \\
\hline
\end{tabular}

Fonte: Elaborada pelos autores deste artigo (2019) 
A Tabela 5, por sua vez, apresenta o resultado geral da pesquisa de patentes na base de dados mundial do Patentscope. Para tal, a pesquisa utilizou a opção de busca any field, que significa "qualquer campo".

Tabela 5 - Resultado geral da pesquisa de patentes na base de dados do Patentscope - opção any field

\begin{tabular}{cc} 
Palavras-chave & Patentscope \\
Trend* and social medi* & 59.402 \\
Trends and social media & 30.185 \\
Trending and social network & 8.462 \\
Social media and analysis & 115.849 \\
Social medi* and API & 66,469 \\
Social medi* and analysis & 159.512 \\
\hline
\end{tabular}

Fonte: Elaborada pelos autores deste artigo (2019)

\section{Considerações Finais}

A realidade do comércio, em especial a prestação de serviços e o consumo, evoluirá e sempre terá novos modelos e novas necessidades. A humanidade se desenvolve e o ato de entender e moldar-se à parte demandante dessa relação significará estar sempre à frente dos demais concorrentes ao se apresentar um produto melhor e mais focado nas reais necessidades dos usuários.

Após definir a estratégia metodológica e a escolha dos indicadores a serem utilizados nas bases de dados internacionais, foram obtidas as informações necessárias para as análises sobre tecnologia de gestão baseada em dados de mídias sociais e tendências - trends.

Foi possível observar que o mundo empresarial e acadêmico apresenta atores bem posicionados que atuam ou são clientes das tecnologias que envolvem a gestão dessas companhias $e$ a percepção dos usuários, independentemente do setor no qual estas atuam, o que, por meio dos gráficos apresentados, restou constatado.

Identificou-se o setor empresarial como líder de depósito das patentes dessa linha tecnológica. Apontou-se que o setor acadêmico também possui um bom percentual de títulos relacionados ao mapeamento principal desta pesquisa.

Os EUA são líderes absolutos em documentos patentários, bem como científicos, e nota-se que empresas-polo nas áreas de programação, comércio varejista e comunicações aparecem como as principais detentoras de patentes relativas a mídias sociais e tendências.

Constatou-se, ainda, por meio da Matriz SWOT, que a tecnologia em estudo possui um equilíbrio entre fortalezas e fraquezas, bem como entre oportunidades e ameaças.

Apesar de considerar que tecnologias que utilizam o suporte de assessoramento a empresas baseado em opinião do cliente (expressa em mídias sociais) estejam consolidadas do ponto de vista da concepção (de não ser inovativo) e do funcionamento, o surgimento de novas mídias sociais ou novos modelos de negócio e softwares permitirá que este mesmo modelo de relação $e$ análise de dados continue em constante aperfeiçoamento. 
Entende-se, pelo exposto neste artigo, que a continuidade do mapeamento, sobretudo considerando-se os demais argumentos de pesquisa apresentados por meio das Tabelas 3, 4 e 5, será capaz de contribuir para estudos dessa natureza em território nacional, visto que o Brasil possui poucos documentos científicos sobre a temática no mapeamento principal desta pesquisa e nenhuma patente, de acordo com a base Espacenet.

Nesse sentido, recomenda-se considerar que a tecnologia API, também apresentada neste artigo, tenha tratamento $e$ foco especiais para um estudo e também mapeamento e prospecção mais complexos no futuro, pois a interação dos dados dos usuários, a serem analisados pelo meio empresarial, coletados nas mídias sociais, necessariamente passará por esta linguagem tecnológica.

Ainda que exista uma gama vasta de trabalhos e patentes, no sentido de entender essa relação entre produção e consumo, o histórico da evolução tecnológica do ponto de vista patentário teve uma aceleração há apenas uma década, com potencial de seguir progredindo, pois o advento das mídias sociais apresenta uma existência de igual período. Conclui-se ainda que há possibilidade de melhoramento da tecnologia analisada.

\section{Referências}

DE ABREU PEREIRA PINTO, Emeline et al. Produção Científica Sobre Redes Sociais: Abordagem Sob a Visão da Administração. Revista FSA, v. 13, n. 4, 2016.

DE MORAES, Thiago Perez Bernardes; SANTOS, Romer Mottinha. Os Protestos no Brasil: Um estudo sobre as pesquisas na web, e o caso da Primavera Brasileira. Revista internacional de investigación en ciencias sociales, v. 9, n. 2, p. 193-206, 2013.

EUROPEAN PATENT OFFICE (EPO). Espacenet: base de dados on-line. [2019]. Disponível em: https://worldwide.espacenet.com/. Acesso em: 12 julho 2019.

KAYSER, Victoria; BIERWISCH, Antje. Using Twitter for foresight: An opportunity? Futures, v. 84, p. 50-63, 2016.

KIETZMANN, Jan H. et al. Social media? Get serious! Understanding the functional building blocks of social media. Business horizons, v. 54, n. 3, p. 241-251, 2011.

MASLOW, Abraham H. A theory of human motivation. Psychological review, v. 50, n. 4, p. 370, 1943.

OliVEIRA, Mariana Corrêa de; CARVALHO, Helenice. Spoleto x Porta dos Fundos: o monitoramento de mídias sociais como ferramenta estratégica na gestão de crises. 2013. Disponível em: https://www.lume.ufrgs.br/handle/10183/88867?show=full. Acesso em: 15 jul. 2018.

QUINTELLA, Cristina Maria et al. Prospecção tecnológica como uma ferramenta aplicada em ciência e tecnologia para se chegar à inovação. Revista Virtual de Química, v. 3, n. 5, p. 406-415, 2011.

SERRA, Bernardo et al. Mídias sociais e negócios: um estudo Delphi. Revista Ibero Americana de Estratégia, v. 12, n. 1, p. 236-253, 2013.

SIMMONS, Geoff. Marketing to Postmodern Consumers: Introducing the Internet. Hameleon European Journal of Marketing, v. 3, n. 4, 2008. 
TECH, Canal. O que é API? 2019. Disponível em: https://canaltech.com.br/software/o-que-e-api/. Acesso em: 26 jun. 2019.

WORLD INTELLECTUAL PROPERTY ORGANIZATION (WIPO). PATENTSCOPE: base de dados on-line. [2019]. Disponível em: https://patentscope.wipo.int/. Acesso em: 10 jul. 2019.

ZACKIEWICZ, Mauro. A economia do software e a digitalização da economia. Revista Brasileira de Inovação, v. 14, n. 2, p. 313-336, 2015.

\section{Sobre os Autores}

\section{Fabrício de Andrade Raymundo}

E-mail: fbi130620@gmail.com

Especialização de Gestão de Segurança Pública.

Endereço profissional: Universidade de Brasília, Campus Darcy Ribeiro, Brasília, DF. CEP: 70910-900.

\section{Eduardo Antonio Ferreira}

E-mail: eduardoantonioferreira@gmail.com

Doutor em Farmácia.

Endereço profissional: Universidade de Brasília, Faculdade de Ceilândia, Campus Universitário, Centro Metropolitano, Ceilândia Sul, Brasília, DF. CEP: 72220-275.

\section{Sônia Marise Salles Carvalho}

E-mail: smarises1960@gmail.com

Doutora em Sociologia.

Endereço profissional: Universidade de Brasília - Campus Darcy Ribeiro, Brasília, DF. CEP 70910-900.

\section{Tânia Cristina Cruz}

E-mail: taniacristina75@gmail.com

Doutora em Sociologia do Trabalho.

Endereço profissional: Faculdade UnB Planaltina/CDT/ PROFNIT, Brasília, DF. CEP: 70904.970.

\section{Leila Fernandes dos Santos}

\section{E-mail: leilabiblioteca@gmail.com}

Mestra em Propriedade Intelectual e Transferência de Tecnologia para Inovação.

Endereço profissional: Universidade de Brasília - Campus Darcy Ribeiro, Brasília, DF. CEP 70910-900.

\section{Marcio Lima da Silva Ph.D}

E-mail: dasilva.marciolima@gmail.com

Doutor em Mecânica dos Fluidos, Processos e Energética pela Universidade de Grenoble,

França (2014).

Endereço profissional: Universidade de Brasília - Campus Darcy Ribeiro, Brasília, DF. CEP 70910-900. 